\title{
Gas Extraction and Necessary Earthquake Regulations
}

\author{
N.P.M. Scholten ${ }^{1, *}$, A.C.W.M. Vrouwenvelder ${ }^{2}$, R.D.J.M. Steenbergen ${ }^{3}$ \\ ${ }^{1}$ Expertcentre Regulations in Building (ERB), Van der Burghweg 1c, Netherlands \\ ${ }^{2}$ Netherlands Organization for Applied Scientific Research (TNO), Van Mourik Broekmanweg 6, Netherlands \\ ${ }^{3}$ Department of Structural Engineering, Netherlands Organization for Applied Scientific Research (TNO), Van Mourik Broekmanweg 6, \\ Netherlands
}

Copyright $\bigcirc 2016$ by authors, all rights reserved. Authors agree that this article remains permanently open access under the terms of the Creative Commons Attribution License 4.0 International License

\begin{abstract}
The northern part of the Netherlands earthquakes is generated by compaction of the reservoir rock on relatively short distance to the surface of the earth, caused by extraction of gas for energy consumption. These so-called induced earthquakes differ from the well-known tectonic earthquakes all over the world. The fact that we have less experience with induced earthquakes than with tectonic ones was the reason to start research and standardization. The impact study learns that possibly up to 300.000 buildings and infrastructural works need to be strengthened, depending on the level of reliability of the structure that will be the regulated. The social commotion in the region is high. There are no regulations for the moment. After recent earthquakes it is now estimated that magnitude in the future will reach 5 on the scale of Richter with peak ground accelerations of $0,4 \mathrm{~g}$. So regulations will be needed. The research program and development of regulations will take a period of at least 3 years. This paper gives the state of affairs of September 2015. Because of societal the topic has a very high ranking on the Dutch political agenda as a result of the serious damage on buildings since the latest earthquakes. In this paper we pay attention to interim rules and first conservative guidelines.
\end{abstract}

Keywords Structural Safety, Earthquakes, Gas Extraction, Liability, Social and Political Impact

\section{Introduction}

\subsection{General}

This paper is the result of desk research, field research, international deliberations and political discussions about earthquakes caused by gas extraction in the Northern part of the Netherlands.

Until recently the Dutch felt empathy for the disastrous effects of earthquakes around the world, assuming that this is an event "far away from us". Although in 1992 a quake happened near Roermond with a magnitude of 5.8 on the Richter scale, which damaged buildings and cars hit by falling debris, but this was not seen as a cause for the introduction of regulations for earthquake resistant structures and the seismic assessment of existing stock. An important argument for this was that in most areas of the Netherlands structures are designed with a high wind action, which, as is often assumed, in the vast majority of cases would dominate over moderate earthquakes. Meanwhile the impact of earthquakes on the built environment was reassessed. This awareness process originated in the earthquakes that happened currently with certain regularity in the province of Groningen (see Figure 1).

These shocks are related to reservoir rock compaction followed by subsidence, caused by gas extraction and therefore have a different cause and other characteristics than most of the quakes occurring abroad. By these phenomena the need is felt in the Netherlands to develop regulation for structures in earthquake zones, as well as to evaluate the structural safety of the existing buildings and infrastructure works. The social commotion in this part of the Netherlands is high which has induced a high pressure to develop policies and measures to accommodate the victims and prevent (further) damage. 


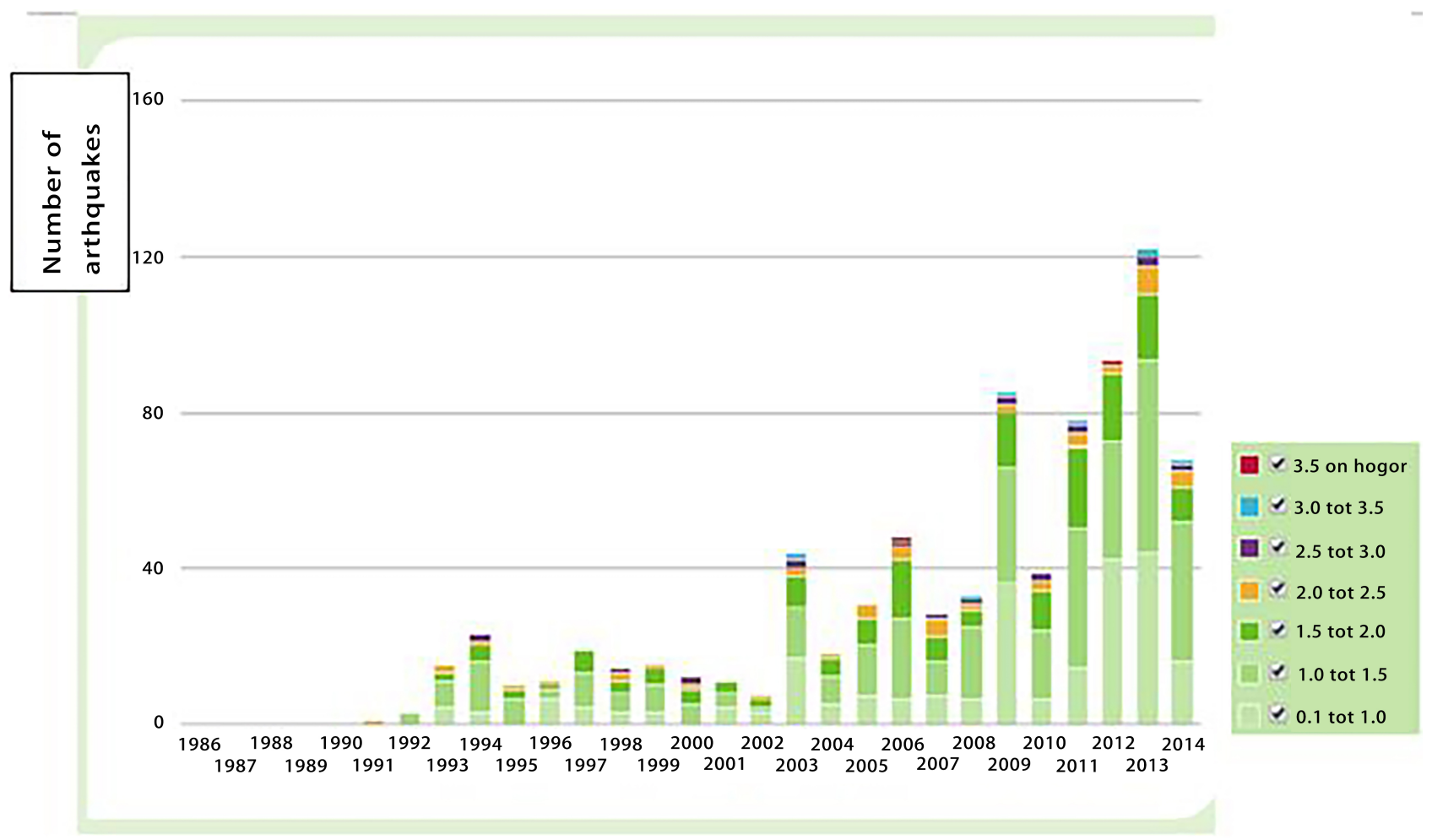

Figure 1. Number of earthquakes in terms of the Richter scale (source NAM Platform) \{measurements before 1991 are too low for registration\}

\subsection{The Cause of Earthquakes}

Earthquakes occur due to shifts in the underground. Usually these are tectonic earthquakes caused by sliding of major tectonic plates. In this sliding process, which occurs very slowly, the edges of the tectonic plates accumulate energy. When the stress becomes so high that a fault occurs, the energy is released, leading to seismic waves through the underground which at the surface leads to vibrations. The place where the elastic energy is released is referred to as the hypocenter in the substrate. The projection of this point perpendicular to the earth's surface is called the epicenter of the earthquake. To indicate the strength of an earthquake the Richter scale is used. This is a measure of the energy released in the hypocenter in the form of elastic waves. This figure is often seen as an indication of the severity of an earthquake. The effect of the energy released in the built environment also depends on the distance from the hypocenter to the surface. The deeper the hypocenter is, the smaller the effect of the earthquake. For the effect of an earthquake to the built environment the intensity of the vibration at ground level is important. The vibration leads normally predominantly to horizontal movements of the soil. In Groningen we see also vertical movements of the same size. The vibrations pass through the foundation in the structure.

The strongest tectonic earthquake observed in the Netherlands struck on 13 April 1992 near Roermond. The magnitude of this earthquake was 5.8 on the Richter scale. The damage due this earthquake was limited because the hypocenter was located at a depth of $17 \mathrm{~km}$.

In Groningen, by contrast, so-called induced earthquakes occur. These occur at approximately $3 \mathrm{~km}$ depth in the sandstone layer, from which natural gas is extracted since 1959 (Fig. 2). From that moment the ground surface dropped by about $0.3 \mathrm{~m}$. Because of the gas extraction the pressure in the sandstone layer decreased, which was then compressed by higher earth layers. The sandstone layer is about $200 \mathrm{~m}$ thick. The tremors accordingly occur probably by shifts along existing old fracture surfaces (about 1500) in the sandstone. The hitherto maximum recorded magnitude on the Richter scale was 3.6, and occurred in the soil near Huizinge in 2012.

So far, the maximum measured ground acceleration is equal to $0.09 \mathrm{~g}$. The number of earthquakes until today registered by the KNMI (Dutch meteorological institute) is about 200. These shakes, with their characteristics, are of great importance for development of calculation rules, as they not only provide information on the intensity of the shocks, but also on the spread in the measured values. This dispersion is a key factor, in combination with the maximum accepted probability to become a victim of a collapse due to earthquakes, to estimate a seismic design load in a probabilistic manner. 


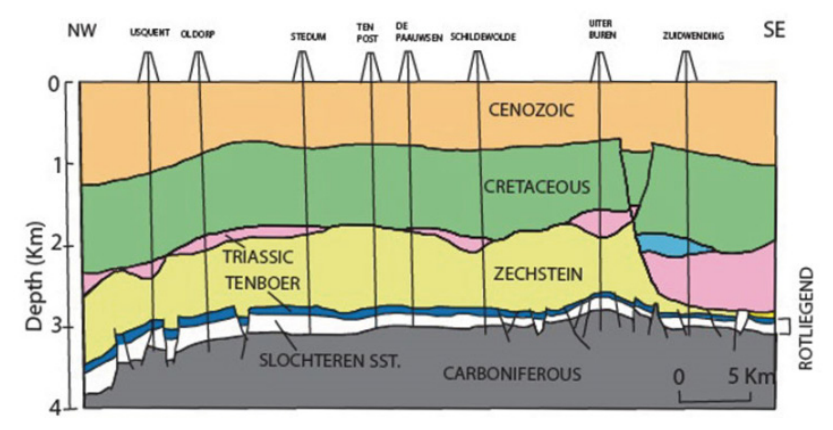

Figure 2. Geological cross section of the Groningen gas field [1]

\subsection{Choices in the Seismic Design}

The requirements to be made to the seismic resistance of a structure depend on which risks of casualties and which extent of damage is considered acceptable. Usually, this is based on a four levels system:

1. The building must be fully operational after the earthquake, with negligible damage and no victims. This especially applies to buildings such as hospitals, police stations, and crisis centers.

2. The building remains operational with minor damage and only minor interruption of non-essential services; no loss of life.

3. The survival rate is very high. Moderate to significant damage is accepted.

4. The building collapses almost: however, the risk of casualties is limited.

\subsection{The Route to Regulations for Seismic Design in the Groningen Region}

At the moment in 2012 where it became clear that for the Groningen region regulations were necessary for seismic design and assessment of the existing stock, the first idea was to refer to EN 1998-1 (Eurocode 8) "Design of structures for earthquake resistance - part 1: general rules, seismic loads and rules for buildings" [2]. This part provides general European rules, with the possibility to fine-tune the content in the National Annex by nationally determined parameters for the Dutch situation. But a first assessment made it clear that this has a lot of drawbacks.

The normative earthquake load must be derived from a relatively limited set of data collected by the KNMI. These must be connected to the Dutch safety philosophy [3] which is anchored in the 2012 Building Decree through NEN 8700. A limited set of data with the corresponding significant variations brings - according to the principles of probabilistic design - high seismic actions that have to be charged, which in the future with more and better data may prove to be too conservative. Maybe uncertainties are then smaller, with less conservative results. Probabilistic design is the best manner to handle uncertainties leading to a minimum of conservatism. It is also important to consider the question which degree of safety is required. The higher the degree of safety required, the greater are the consequences for the area. That concerns especially the existing buildings, which are not designed for seismic actions. There is often a stacked construction without proper connections between floors and walls. The resilience of these constructions is an important aspect in the assessment of the safety of the built environment. A thorough analysis is required of the behavior of the different types of structures ranging from dwellings to offices and high-rise buildings. The mainstream construction methods in the Netherlands differ from those in other countries, especially when it comes to masonry structures. Studies into the behavior of typical Dutch types of structures are running.

In the EN 1998 standard series a behavior factor of structures is employed to simplify the calculations. For behavior factor q good recommendations should be given: i.e. values that ensure adequate safety, but not so conservative that the effects are disproportionate. This irrespective of methods to accurately determine the behavior in specific situations. These methods are very costly. In the Groningen area there are many masonry structures, which in case of too generally formulated criteria lie in the critical area which would not be the case in a more sophisticated analysis. The values of the behavior factor q of Eurocode 1998 are not tailored to Dutch construction methods.

Furthermore, the soil in the Dutch situation is yet insufficiently classified.

It is estimated that a well-founded set of the national parameters takes a period of three years to develop. The acute situation in Groningen however asks to act with more speed. The Ministry of Economic Affairs has indicated that a regulation should be available within one year.

To address this, it was decided to develop an NPR (Dutch Practice Guideline), under the supervision of a committee of experts set up by NEN working on NPR 9998 "Design and evaluation of earthquake-resistant buildings in construction, renovation and disapproval - Basic rules for seismic act ions; Induced earthquakes" [4] This NPR 9998 offers clients, designers and contractors a (technical) guidance in new construction and in 'preventive repair' of buildings. The content of this guideline is as follows:

$$
\begin{array}{cc}
\begin{array}{c}
\text { 1. General } \\
\text { 2. Performance requirements and } \\
\text { eligibility criteria }
\end{array} & \begin{array}{c}
\text { 8. Specific rules for timber } \\
\text { structures }
\end{array} \\
\begin{array}{c}
\text { 3. Soil conditions and seismic } \\
\text { loads }
\end{array} & \begin{array}{c}
\text { 9. Specific rules for masonry } \\
\text { structures }
\end{array} \\
\begin{array}{c}
\text { 4. Design and redesign of } \\
\text { buildings }
\end{array} & \begin{array}{l}
\text { 10. Specific rules for foundations } \\
\text { Annexes }
\end{array} \\
\begin{array}{c}
\text { 5. Specific rules for concrete } \\
\text { structures }
\end{array} & \begin{array}{c}
\text { A: Inspection Protocol } \\
\text { B: Strengthening Protocol }
\end{array} \\
\begin{array}{c}
\text { 6. Specific rules for steel } \\
\text { structures }
\end{array} & \begin{array}{c}
\text { C: Application of NPR to large } \\
\text { numbers of buildings }
\end{array} \\
\begin{array}{c}
\text { 7. Specific rules for steel and } \\
\text { concrete structures }
\end{array} & \text { D: Earthquakes (background) }
\end{array}
$$

The release of the first draft of NPR 9998, published in January 2015 for external comments, as an interim solution has several advantages: 
- In preparing the NPR much information is obtained that can serve as input for the later to be published Dutch version of EC8 and associated National Annexes. This study is planned to continue intensively up to 2017 .

- The recommendations of the NPR can be adjusted relatively quickly when needed. If during the development of the later to be published Dutch version of Eurocode yields important new data and insights, these can also be used, for example within a year, to publish an updated version of the NPR.

The NPR has the status of a recommendation and is not part of the law, as it is not referred to by the 2012 Building Decree. The publication of the first agreed version of the NPR was foreseen September 2015.

In May 2014, prior to the NPR an "Interim advice earthquake resistant construction" [5] was published. The aim was to prevent that new construction projects in the region Northeast Groningen grind to a halt until the NPR is available. In the interim advice the provisional principles for new construction and renovations are set related to seismic actions in the province of Groningen.

\section{Regulations}

\subsection{Fundamental Requirements}

The fundamental requirements demanded for structures have a relationship with the degree of damage to the building structure, distinguishing three limit states:

- The building construction is almost collapsing (Near Collapse, NC);

- $\quad$ Significant damage (Serious Damage, SD);

- Harm (Damage Limitation, DL).

In the interim advice and the NPR the choice has been made for a further elaboration of the NC level because it has a direct relationship with preventing victims. That is the primary task for the government. Indications are given for citizens who would like to choose the level SD.

\subsection{Safety Level}

The level of safety that is associated with' a particular limit state depends on the consequences when exceeding it. Effects may be related to economic losses, environmental damage and deaths or injuries. For earthquakes, in particular limit state Near Collapse is associated with casualties.

In determining the target level of safety legal requirements applicable in other situations should also be considered.

The risk of death due to an accident (traffic, falling down stairs, etc.) in the Netherlands is about $10^{-4}$ per year. Here the rule is applied that the risk of death due to structural failure should be significantly lower than other risks faced by people in everyday life. It is generally accepted that the risk of casualties due to structural failure should be a factor of 10 to 100 smaller than the chance of an ordinary accident.

In preparing NEN 8700 [6] it was the starting point that a probability of $\mathrm{P}=10^{-5}$ per year is considered acceptable to victims of structural failure; this value is therefore as such legally enshrined in the 2012 Building Decree [7] Earthquakes are set on the same probability in the NPR.

In the case the safety level would be based on the environmental legislation (gas extraction falls under the Environmental Protection Act [8], the limit is a maximum individual risk of $10^{-6}$. In the NPR this is neglected for practical reasons.

This requirement can be converted to a probability of failure in the various consequence classes (CC1-CC3 according to EN 1990 and NEN 8700). For this, information on the risk of casualties in the case of the failure of the structure is required.

In the background study of the NPR [9] the following reliability indices $(\beta)$ are derived.

Table 1. $\beta$-values for the minimum reference period, earthquakes, reduced requirements for new construction, renovation and disapproval

\begin{tabular}{|c|c|c|c|c|}
\hline Consequence class & $\begin{array}{c}\text { Minimum } \\
\text { Reference period for } \\
\text { disapproval }\end{array}$ & New structure & $\beta_{\mathrm{n}}$ & $\beta_{\mathrm{r}}$ \\
\hline CC1A & 1 year & 3.0 & 1.8 \\
CC1B & 15 years & 3.0 & $2.8^{*}$ \\
CC2 & 15 years & 3.2 & $3.0^{*}$ \\
CC3 & 15 years & 3.6 & $3.4^{*}$ \\
\hline
\end{tabular}




\subsection{Seismic Action}

A newly built or modified construction and an existing building structure should, depending on the consequence classes (CC) as defined in NEN-EN 1990 or NEN 8700, be constructed so that they can withstand the consequences of seismic action, determined with the data set out in Table 2.

\subsection{Peak Ground Acceleration}

In the interim advice and draft NPR a map is included with peak ground accelerations with an annual exceedance probability of $0.2 \%$. The map with peak ground accelerations is partly based on an extrapolation of previous earthquakes recorded by the KNMI [10]. Since this is a relatively small number of data and it was necessary to make a number of assumptions in order to produce this map, the values chosen for the peak ground acceleration are possibly conservative (high).

In the centre of the map is the village Loppersum, where the largest horizontal loads are expected (to be calculated on the basis of a peak ground acceleration of $0.42 \mathrm{~g}$ ). The horizontal PGA decreases from Loppersum with each ring and this may also generally decrease the impact of the structural measures needed.

On the map peak ground accelerations are displayed of up to $0.1 \mathrm{~g}$. It is expected that the majority of houses built according to current building methods (without or with minimal strengthening measures) are sufficiently secure against earthquakes, caused by peak ground accelerations of up to $0.1 \mathrm{~g}$. As "minimal measures" for seismic resistance the interconnection of sufficiently rigid walls and floors can be considered.

Figure 3 represents the location-dependent PGA values (Peak Ground Acceleration) for a standard return period of 475 years as used in EN 1998.

Conversion can be done according to Table 2 required return periods by multiplying with the importance factors ${ }_{\gamma} \mathrm{I}$ -according Table 3.

Table 2. Minimum reliability and parameters for the setting of the design values of the earthquake action

\begin{tabular}{|c|c|c|c|c|c|c|c|c|}
\hline \multicolumn{9}{|c|}{ Reliability level ${ }^{\mathrm{a}}$} \\
\hline \multirow{3}{*}{ Consequence class } & \multicolumn{4}{|c|}{ New structure ${ }^{b}$} & \multicolumn{4}{|c|}{ Renovation and disapproval } \\
\hline & \multicolumn{2}{|c|}{$\mathrm{CC} 1^{\mathrm{c}}$} & \multirow{2}{*}{$\mathrm{CC} 2$} & \multirow{2}{*}{$\mathrm{CC} 3$} & \multicolumn{2}{|c|}{$\mathrm{CC} 1^{\mathrm{c}}$} & \multirow{2}{*}{$\mathrm{CC} 2$} & \multirow{2}{*}{$\mathrm{CC} 3$} \\
\hline & $\mathrm{CC} 1 \mathrm{~A}$ & CC1B & & & $\mathrm{CC} 1 \mathrm{~A}$ & $\mathrm{CC} 1 \mathrm{~B}$ & & \\
\hline \multirow{3}{*}{$\begin{array}{c}\boldsymbol{B} \\
T_{\mathrm{ref}}[\text { years }] \\
\text { return period for } T_{\mathrm{NCR}} \text { related to } \\
a_{\mathrm{gd}}[\text { years }] \\
\end{array}$} & - & 3,0 & 3,2 & 3,6 & - & 2,8 & 3,0 & 3,4 \\
\hline & - & 50 & 50 & 50 & - & 15 & 15 & 15 \\
\hline & - & 1200 & 1800 & 3600 & - & 800 & 1500 & 3000 \\
\hline \multicolumn{9}{|c|}{$\begin{array}{l}\text { a. When comparing the beta-values it must be taken into account that the reliability requirement for a new structure is valid for a longer period of } \\
\text { time } \\
\text { b. Under new structure is also understood the renewal of an existing structure as a whole building } \\
\text { c. Class } \mathrm{CC} 1 \text { is split for earthquakes in a class } \mathrm{CC} 1 \mathrm{~A} \text { (no risk for human life) and CC1B (low risk to human life). For CC1A earthquake resistant } \\
\text { design is not considered to be necessary. If desired, by private decision for new structures in CC1 A the values } 3.0,1 \text {, and } 350 \text {, can be taken for } \\
\text { respectively } \beta, T_{\text {ref }} \text { and return period. For private renovation and disapproval statements the values } 1.8,1 \text {, and } 200 \text { can be taken for respectively } \\
\beta, T_{\text {ref }} \text { and return period. }\end{array}$} \\
\hline
\end{tabular}

Table 3. Importance Factors ${ }_{\gamma} \mathrm{I}$ for various consequence classes and assessment situations (Near Collapse)

\begin{tabular}{|c|c|c|c|}
\hline & \multirow{2}{*}{ Consequence class } & \multicolumn{2}{|c|}{ Importance factor ${ }_{\gamma} \mathrm{I}$} \\
\hline & & New structure & Renovation and disapproval \\
\hline & CC1A & $\mathrm{a}$ & $\mathrm{b}$ \\
\hline & $\mathrm{CC} 1 \mathrm{~B}$ & 1,3 & 1,2 \\
\hline & $\mathrm{CC} 2$ & 1,5 & 1,4 \\
\hline & $\mathrm{CC} 3$ & 1,7 & 1,6 \\
\hline $\mathrm{a}$ & $\begin{array}{l}\text { For } \mathrm{CC} 1 \mathrm{~A} \text { earthquake ac } \\
\text { For } \mathrm{CC} 1 \mathrm{~A} \text { earthquake } 1\end{array}$ & $\begin{array}{l}\text { cisive. If desired, } \\
\text { isive. If desired, }\end{array}$ & $\begin{array}{l}\text { nce factor of } 0.8 \text { must be observed. } \\
\text { ficance factor of } 0.6 \text { must be observed. }\end{array}$ \\
\hline
\end{tabular}




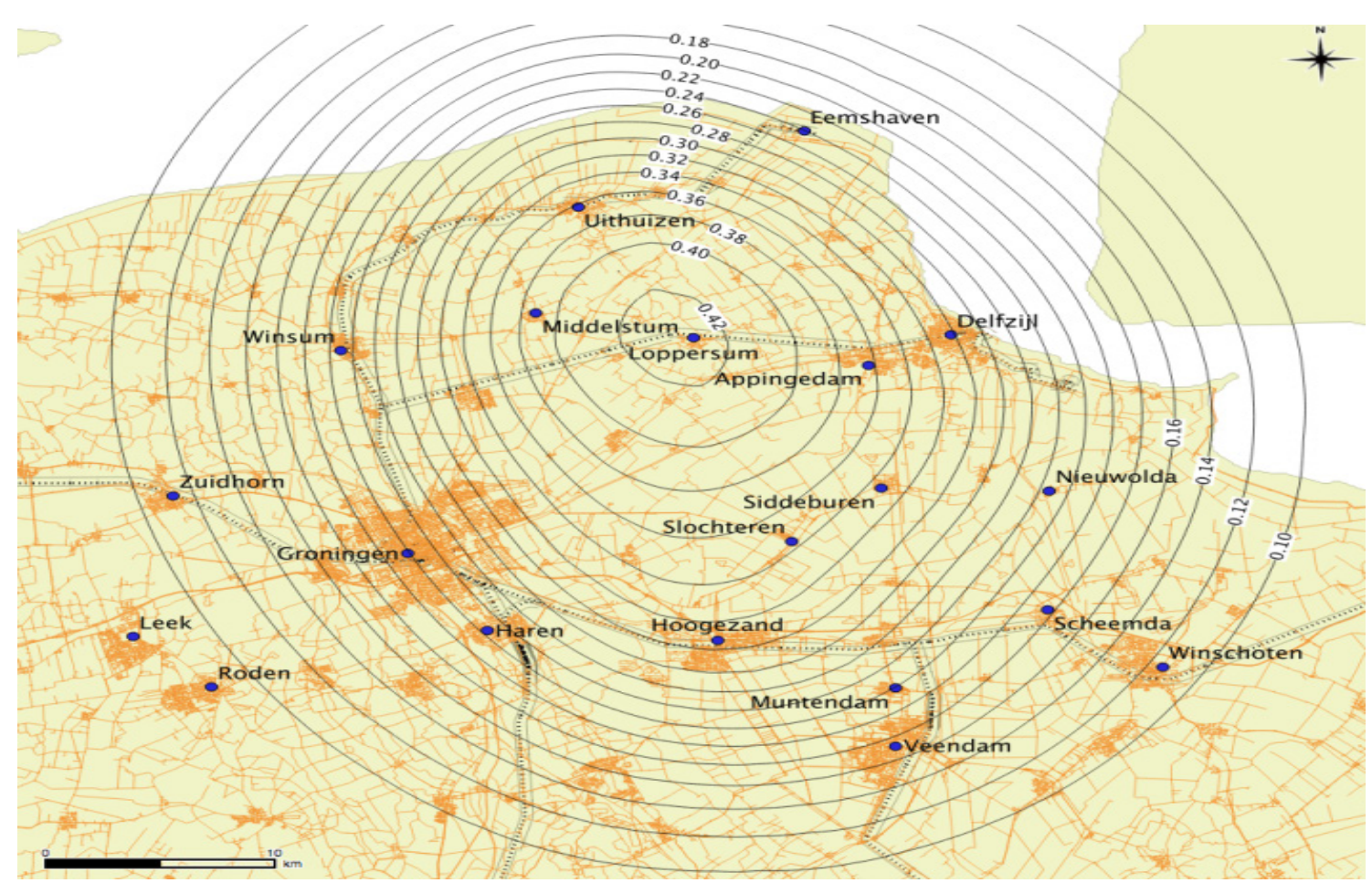

Figure 3. Contour Plot of the peak ground accelerations ag,ref in $[\mathrm{g}=10 \mathrm{~m} / \mathrm{s} 2]$ at ground level with a return period of 475 years (source KNMI)

\subsection{Seismic Resistance}

The following calculation methods are available:

A: Lateral force method

B: Modal response

C: Pushover analysis

D: Non-linear dynamic calculation.

Within the range $\mathrm{A}$ thru $\mathrm{D}$, the quality of the estimation of the reliability of the structure improves by applying a more advanced method. Only the most advanced agencies are able to do non-linear dynamic calculations. The number of structures that must be assessed in the relatively short term and the costs of assessment determine that not everything can be evaluated using these most advanced techniques. To avoid that too many buildings are unnecessarily rejected, more simple methods are also given that approach the outcome of a non-linear dynamic calculation as well as possible. However, the NPR may still lead to results that are to be considered as conservative.

The draft NPR contains for structures of concrete, steel, wood, composite steel concrete and masonry first methods to determine their strength under induced earthquakes, tailored to Dutch construction methods.

\subsection{Collapse of the soil}

Only limited information is available on the behaviour of the soil under induced earthquakes. The soil in the northern Netherlands is peculiar. Softening of the ground can cause both horizontal and vertical displacements, as well as a decrease in the strength of the ground. Compaction of the ground can have the same effects. The NPR gives first indicative assessment methods for the degree of softening and liquefaction and its influence on the structures. Also this part may be quite conservative.

\section{Impact Analysis}

Because of the severe social commotion and given the major economic consequences of suddenly imposed new regulation, the Ministry of Economic Affairs commissioned an impact study. How many buildings are insufficiently safe? Are they really unsafe, when calculated with the perhaps too conservative calculation methods based on the limited knowledge about induced earthquakes on the one hand, and the peculiarities of the structural behaviour of Dutch construction methods on the other hand? Where to begin when investigating the reliability of more than 300.000 buildings? Where to start taking measures to strengthen existing structures? To which safety level should refurbishment at least lead? As said before, taking into account the still limited knowledge: with the knowledge of today there is an annual risk of casualties by failure of the structure of $10^{-4}$, while perhaps within a few years in the same building the risk of casualties proves to be $10^{-5}$ ? When balancing the discussion the required economic efforts also obviously play a major role. The cost consequences can widely differ.

\section{Next Steps and Further Research}

The next phase of the development of the regulations is in 
the pipeline. Further research will lead to more insight in future seismic actions and in the behaviour of existing structures in that region. This knowledge can improve the NPR and the details of the national annexes of EN 1998 series in the future for the Netherlands.

Political and administrative consultation will be organised on the embedding of the requirements in the 2012 Building Decree. Also administrative consultation will be held about the financial loss for all owners and users of buildings in the region. Accordingly the discussion will be started about infrastructural works and industrial facilities that are present in this area and require strengthening.

It will also be important how the government will handle the extraction of gas and winning of alternative energy. Will we continue to produce natural gas, where and in what quantity and with which speed? What impact does this have on the number of buildings in the "danger zone? What are the implications of a possible shift to shale gas exploitation? What to do with nuclear energy? What will be the impact of energy neutral buildings?

\section{Conclusions}

The Netherlands stands for a huge challenge technically, politically and administratively as a result of gas extraction in the north-eastern part of the country. Technically it involves:

a. catching up on knowledge for earthquake resistant construction;

b. the statistical determination, as well as possible, of the emerging induced earthquakes in the future;

c. determination of the behaviour of known Dutch construction methods under induced earthquake actions;

d. developing proportional strengthening measures for all existing buildings;

e. developing new earthquake-resistant construction methods;

f. developing regulations for earthquake resistant building within the constraints of the Dutch legislation.

This requires an enormous research and development program in the next two years. In the meantime provisional technical decisions will be taken under government pressure, based on poor knowledge of all important aspects.

Political and administrative decisions will be taken on the embedding of the consequences of earthquakes in the regulations and on the level of requirements, which may change in time due to the developments in scientific knowledge. Decisions also have to be taken on the compensation of economic loss. The energy supply and energy demand of the Netherlands may have to be reassessed. To a considerable extent the demand for natural gas will determine the occurrence of earthquakes in the future.

After two years of study we are only at the beginning, but the severe impact on the built environment and its inhabitants imposes the need for quick first decisions.

\section{REFERENCES}

[1] [Ken Glennie, Eppo Oomkens and the Discovery of Groningen Gas, AAPG Explorer, September 2013

[2] NEN-EN 1998, Eurocode 8 "Design of structures for earthquake resistance - Part 1: General rules, seismic actions and rules for buildings" NEN, 2005

[3] Vrouwenvelder (TNO) Prof. A.C.W.M., Scholten (ERB), Dr ir N.P.M., Steenbergen (TNO), Dr ir R D.J.M. Safety assessment of existing stock. Background report by NEN 8700, TNO-060-DTM-2011-03086), December 2011 (Dutch)

[4] Draft NPR 9998, Assessment of buildings in case of erection, reconstruction and disapproval - Basic rules for seismic actions; Induced earthquakes, NEN, January 2015, (Dutch)

[5] Steenbergen (TNO), Prof Dr. ir. R.D.J.M., Vrouwenvelder (TNO), prof. ir. A.C.W.M., Korff (Deltares), dr. ir. M., Scholten (ERB), dr.ir. N.P.M. en Eck (KNMI) $\dagger$ ), dr. T. van, Preliminary design parameters for newly built buildings en renovation in case of seismic design related to gas extraction in the gas field of Groningen, 7 May 2014, NEN, (Dutch)

[6] NEN 8700, Assessment of existing structures in case of reconstruction and disapproval - Basic Rules, 2011, NEN (Dutch)

[7] 2012 Building Decree, Decree of 29th of August 2011 laying down regulations for the construction, use, and demolition of structures (Building Decree 2012), Official Gazette 2011, 416, 27 September 2011, BZK, (Dutch)

[8] Environmental Management Act, I\&M, Act of 13 June 1979, Laying down rules related to general subjects in the field of environmental health, Official Gazette 1979, 442, 13 June 1979 (Dutch)

[9] Steenbergen, R.D.J.M. , Vrouwenvelder, A.C.W.M., Scholten (ERB), N.P.M., Safety considerations earthquakes, TNO 2013 R12071, TNO report, 9 April 2015 (Dutch)

[10] Eck†, T. van, Caccavale, M., Dost, B. Kraaijpoel, D., Probabilistic Seismic Hazard Analyses Induced Earthquakes Groningen, KNMI, 2014, March 2014 